\title{
AVALIAÇÃO DO GASTO E CONSUMO VOLUNTÁRIO DE RAÇÕES BALANCEADAS E SEMENTE DE GIRASSOL PARA PAPAGAIOS-VERDADEIROS (Amazona aestiva)
}

\author{
Voluntary intake of commercial foods and sunflower seed for blue-fronted parrot (Amazona aestiva) \\ Carlos Eduardo do Prado Saad', Walter Motta Ferreira², Flávia Maria de Oliveira Borges ${ }^{3}$, \\ Leonardo Boscoli Lara ${ }^{4}$
}

\begin{abstract}
RESUMO
Utilizou-se de 12 papagaios adultos, distribuídos em blocos ao acaso em seis tratamentos (Ração extrusada para psitacídeos, Ração peletizada para psitacídeos, Ração comercial extrusada para psitacídeos, Ração extrusada para cães linha prêmio; Ração extrusada para cães linha econômica e Semente de Girassol), durante três períodos de cinco dias de colheita, com 7 dias de adaptação entre colheitas, totalizando seis repetições por tratamento, em que foram avaliados o gasto total (matéria seca - MS e matéria natural - MN) e o consumo total de MN, MS, proteína bruta (PB), energia metabolizável aparente e verdadeira corrigidas pelo N (EMAn e EMVn), cálcio $(\mathrm{Ca})$ e fósforo $(\mathrm{P})$, por ave e por quilograma de peso metabólico. As médias obtidas foram comparadas pelo teste SNK. Os resultados obtidos permitiram concluir que: 1- os consumos médios de MS foram influenciados negativamente pelo teor de energia metabolizável da dieta; 2- o alto consumo das aves recebendo semente de girassol sugere que, além da densidade energética, a palatabilidade da dieta tem grande influência no consumo voluntário; 3- todas as dietas testadas atenderam as necessidades diárias de proteína bruta; 4- o consumo de cálcio da semente de girassol não atendeu a necessidade diária do elemento. 5- o tamanho do grânulo parece interferir no gasto e desperdício de ração pelas aves.
\end{abstract}

Termos para indexação: Consumo voluntário, psitacídeos, nutrição.

\begin{abstract}
Were used 12 adult parrots, distributed in blocks in six treatments (Extruded food for psittacines, Pelleted food for psittacines, Extruded commercial food for psittacines, Extruded dogs food premium line; Extruded dogs food economic line and Sunflower Seed). during three periods, in six repetitions for treatment. The total expense (dry matter evaporates - DM and natural matter - NM) and intake of NM, DM, crude protein (CP) apparent and true metabolizable energy N corrected (AME $\mathrm{n}$ and TMEn), calcium (Ca) and phosphorus $(\mathrm{P})$, was evaluated for bird and for kilogram of metabolic size. The data were collected in three experimental phases of five days each, and previously to each phase an adaptation of seven days was accomplished to the experimental diets. The averages were compared by the SNK test. The obtained results allowed to conclude that: 1 - the medium consumptions of DM were influenced negatively by the metabolizable energy of the diet; 2 - the high intake of the birds receiving sunflower seed suggests that, besides the energy density, the flavor of the diet has great influence in the voluntary feed intake; 3 - all the tested diets reach the daily requirement of crude protein; 4 - the calcium intake of the sunflower seed did not reach the daily requirement of this nutrient, 5- the bigger pellet size seems to influenced negatively the total waste of parrot food.
\end{abstract}

Index terms: Voluntary intake, psittacines, nutrition.

(Recebido em 4 de novembro de 2005 e aprovado em 8 de maio de 2006)

\section{INTRODUÇÃO}

A disponibilidade de rações comerciais para aves ornamentais ainda é muito pequena quando comparada ao consumo potencial. As rações comerciais devem, além de fornecer os princípios nutritivos em quantidades adequadas para atender às necessidades das aves, incluir uma série de outros aspectos nutricionais como qualidade da matériaprima e palatabilidade (MACHADO \& SAAD, 2000). Devido à pouca disponibilidade de alimentos comerciais específicos para psitacídeos, é prática corrente em criadouros e em zoológicos, a oferta de rações não específicas, como rações para frangos de corte ou rações para cães, além de uma mistura de diversas sementes, como alpiste, amendoim e girassol, que é oferecida à vontade.

As deficiências nutricionais são as causas mais comuns de doenças em psitacídeos domésticos, devido ao fato da maioria dos alimentos para papagaios,

\footnotetext{
Zootecnista, D.Sc.Nutrição de Animais Silvestres - AnimalNutri (Consultoria em Nutrição Animal) - Rua Dr. Armando Amaral, 122 - Bairro Padre Dehon - 37.200-000 - Lavras, MG - eduardosaad@animalnutri.com.br; saadzoo@ufla.br

2Zootecnista, D. Sc. - Professor Adjunto - Escola de Veterinária da Universidade Federal de Minas Gerais/UFMG - Av. Antônio Carlos, 6627 - Bairro Pampulha - 30.123-970 - Belo Horizonte, MG - waltermf@vet.ufmg.br

${ }_{3}^{3}$ Médica Veterinária, D.Sc., Professora Adjunta, Departamento de Zootecnia/DZO - Universidade Federal de Lavras/ UFLA - Cx. P. 3037 - $37200-000$ Lavras, MG.

${ }^{4}$ Médico Veterinário, D.Sc. - Nutriara - Rua Jurutau, 1800 - Bairro Parque Industrial II - 86.703-070 - Arapongas, PR - leoboscoli@gmail.com
} 
comercialmente disponível, ser à base de misturas de sementes multi-deficientes. Além disso, os pássaros comem seletivamente, o que pode levar a um desequilíbrio nutricional dos alimentos ingeridos (LUMEIJA et al., 1996).

Uma vez em cativeiro, as necessidades nutricionais das aves modificam-se amplamente. É fácil imaginar que essas aves em seu habitat voam, muitas vezes quilômetros, para conseguir alimentos, com uma necessidade energética muito mais elevada que aves mantidas em gaiolas ou até mesmo grandes viveiros (CARCIOFI \& SAAD, 2001). Além disso, a sazonalidade e a oferta de alimentos impõem a essas aves períodos de carência e fartura. Essa forma natural faz com que as aves obrigatoriamente consumam pequenas, mas variadas quantidades de grãos, insetos, flores, frutos, etc (ULLREY et al., 1991).

Além do gasto energético com a atividade física, resultante da queima de lipídeos corporais, as aves, em seu hábitat natural, devem ingerir quantidades extras de energia, de modo a estabelecer um depósito corporal de gordura. Esses depósitos têm o seu papel preponderante como reserva para épocas de escassez alimentar ou na reprodução (SAAD \& MACHADO, 2000).

Em cativeiro, as aves não têm grande atividade física e o alimento é fornecido de forma constante e, em geral, em quantidades superestimadas. O excesso de energia é estocado no organismo da ave como tecido adiposo. Esse acúmulo de gordura pode ter conseqüências graves na reprodução das aves, no desencadeamento de doenças como a do fígado gordo e doenças cardiovasculares (SAAD \& MACHADO, 2000).

Segundo Nunes (1998), o consumo de energia metabolizável é bem estabelecido em animais monogástricos adultos. Se existe um aumento da concentração de energia da dieta, o consumo de energia líquida não é alterado, pois se reduz o consumo de matéria seca dessa dieta. Caso ocorra uma diminuição da densidade energética da dieta, espera-se que o consumo aumente, entretanto, a palatabilidade é um fator que pode também interferir no consumo voluntário do animal, sobrepondose ao teor energético da dieta.

Objetivou-se com este trabalho, avaliar através do gasto e do consumo involuntário as dietas comerciais específicas para psitacídeos, as não específicas, como dietas para cães e a semente de girassol na alimentação de papagaios-verdadeiros.

\section{MATERIAL E MÉTODOS}

Foram utilizados 12 papagaios-verdadeiros (Amazona aestiva) adultos, distribuídos ao acaso em seis tratamentos durante três períodos de colheita, totalizando seis repetições por tratamento (36 unidades experimentais). As aves foram alojadas individualmente em gaiolas metabólicas durante todo o período experimental, em uma sala de metabolismo inteiramente fechada e climatizada com ar condicionado.

Os tratamentos experimentais foram: 1- Ração extrusada para psitacídeos; 2- Ração peletizada para psitacídeos; 3 - Ração comercial extrusada para psitacídeos; 4- Ração extrusada para cães linha prêmio; 5- Ração extrusada para cães linha econômica e 6Semente de Girassol. As rações do tratamento um e dois foram obtidas utilizando-se a mesma formulação, os mesmos ingredientes em quantidades idênticas, diferindo apenas no modo de processamento; extrusão e peletização, respectivamente. Já o tratamento três refere-se a uma outra ração extrusada para psitacídeos encontrada no mercado.

A avaliação do gasto de ração total foi feita registrando-se o peso inicial das rações oferecidas menos o peso final das sobras no comedouro. O consumo total foi obtido registrando-se o peso inicial das rações oferecidas menos o peso final das sobras no comedouro e o desperdício nas bandejas coletoras. Para a avaliação da semente de girassol, foi considerada a relação $65,83 \%$ de semente e $34,17 \%$ de cascas, sendo essa porcentagem obtida descascando-se manualmente 500 gramas de sementes.

Os parâmetros avaliados foram o gasto total (matéria seca - MS e matéria natural - MN) e consumo total de MN, MS, proteína bruta (PB) energia metabolizável aparente e verdadeira corrigidas pelo $\mathrm{N}$ (EMAn e EMVn), cálcio (Ca) e fósforo $(\mathrm{P})$, por ave e por peso metabólico.

As análises das amostras das rações e semente de girassol (Tabela 1) foram realizadas segundo a metodologia da AOAC (CUNNIFF, 1995), para MS, Matéria orgânica (MO), Matéria Mineral (MN), PB, Fibra Bruta (FB), Extrato Etéreo (EE), Ca e P. A medida de energia bruta $(\mathrm{EB})$ foi realizada em calorímetro adiabático PARR (ASTM, 1971).

Para estimar o consumo de EMAn e EMVn foram utilizados os valores obtidos "in vivo" por Saad (2003), descritos na Tabela 2.

O procedimento estatístico adotado foi o GLM do pacote estatístico SAS Institute (1995). O delineamento foi em blocos ao acaso, com seis tratamentos (t), três períodos experimentais $(\mathrm{k})$, e seis repetições $(\mathrm{r})$. As médias foram comparadas pelo teste Student Newman Keuls para observação de todos os efeitos. 
TABELA 1 - Análises químicas (\%) e valores de energia bruta (kcal/g) das dietas experimentais. ${ }^{1,2} 3$

\begin{tabular}{lrrrrrrrrrrr}
\hline \multicolumn{1}{c}{ Dietas experimentais } & MS & MO & EB & PB & FB & EE & Cz & ENN & Ca & $\begin{array}{c}\text { P } \\
\text { Relação } \\
\text { Ca:P }\end{array}$ \\
\hline Ração extrusada para psitacídeos & 91,7 & 87,0 & 4560 & 18,0 & 2,3 & 7,2 & 5,2 & 67,3 & 0,99 & 0,87 & $1,14: 1$ \\
Ração peletizada para psitacídeos & 90,4 & 85,2 & 4566 & 17,4 & 3,3 & 7,3 & 5,7 & 66,5 & 1,06 & 0,89 & $1,19: 1$ \\
Ração comercial extrusada para psitacídeos & 91,1 & 88,3 & 4842 & 23,3 & 0,9 & 8,6 & 3,1 & 64,2 & 0,31 & 0,58 & $0,53: 1$ \\
Ração extrusada para cães linha prêmio & 92,4 & 87,4 & 5230 & 28,6 & 2,5 & 19,1 & 5,5 & 44,3 & 1,03 & 1,08 & $0,95: 1$ \\
Ração extrusada para cães linha econômica $^{4}$ & 91,3 & 85,4 & 4397 & 18,4 & 4,0 & 8,0 & 6,4 & 63,2 & 2,16 & 1,10 & $1,96: 1$ \\
Semente de Girassol $^{4}$ & 95,9 & 93,1 & 7643 & 24,8 & 2,9 & 57,8 & 3,0 & 12,2 & 0,06 & 1,05 & $0,06: 1$ \\
\hline
\end{tabular}

1- Dados expressos na base da matéria seca.

2- Análises realizadas no Laboratório de Nutrição da Escola de Veterinária da UFMG e no Laboratório de Nutrição do instituto Mineiro de Agropecuária.

3- $\mathrm{MS}=$ matéria seca, $\mathrm{MO}=$ matéria orgânica, $\mathrm{EB}=$ energia bruta, $\mathrm{PB}=$ proteína bruta, $\mathrm{FB}=$ fibra bruta, $\mathrm{EE}=$ extrato etéreo, $\mathrm{Cz}=$ cinzas, $\mathrm{ENN}=$ Extrativo não nitrogenado, $\mathrm{Ca}=$ Cálcio, $\mathrm{P}=$ Fósforo.

4- Valores na semente de girassol descorticada manualmente.

TABELA 2 - Valores de energia metabolizável aparente corrigida pelo nitrogênio (EMAn) e verdadeira corrigida pelo nitrogênio (EMVn), em kcal/kg de MS, das dietas experimentais ${ }^{1}$.

\begin{tabular}{|c|c|c|c|}
\hline Dietas experimentais & & EMAn & EMVn \\
\hline Ração extrusada para psitacídeos & 3370,5 & $\pm 44,0$ & $3415,0 \pm 34,4$ \\
\hline Ração peletizada para psitacídeos & 3241,5 & $\pm 136,4$ & $3289,4 \pm 112,7$ \\
\hline Ração comercial extrusada para psitacídeos & 3628,1 & $\pm 106,1$ & $3665,3 \pm 97,9$ \\
\hline Ração extrusada para cães linha prêmio & 3976,5 & $\pm 85,2$ & $4031,4 \pm 64,0$ \\
\hline Ração extrusada para cães linha econômica & 3012,4 & $\pm 158,9$ & $3042,7 \pm 139,9$ \\
\hline Semente de Girassol ${ }^{2}$ & 6884,2 & $\pm 65,8$ & $6942,0 \pm 59,2$ \\
\hline
\end{tabular}

1 -Dados obtidos de Saad (2003).

2- Valores na semente de girassol descorticada manualmente.

\section{RESULTADOS E DISCUSSÃO}

Na Tabela 3, encontram-se os valores para o gasto e o consumo diário das dietas na MN e MS, respectivamente, por ave. O gasto é importante para os criadores, pois reflete efetivamente o que será utilizado em alimentos no criatório. Já o consumo permite avaliar se a quantidade de um determinado alimento ingerido voluntariamente é suficiente para atender às necessidades de nutrientes recomendados para cada fase; neste caso, a manutenção de papagaios adultos.

Não foi encontrada diferença $(\mathrm{P}>0,05)$ para o gasto, tanto em MN quanto MS, entre os tratamentos, com exceção as rações para cães da linha econômica, com um maior gasto de 179,47 gramas por ave/dia (MS).

Os valores observados para o consumo por ave/ dia, em MN, apenas a ração extrusada para cães linha prêmio e a semente de girassol $(18,33 \mathrm{~g}$ e $17,74 \mathrm{~g}$, respectivamente) diferiram, para menor, $(\mathrm{P}<0,05)$ da ração extrusada para cães linha econômica. As rações extrusada e peletizada para psitacídeos e extrusada comercial para psitacídeos não apresentaram diferenças estatísticas entre si e entre as demais rações. Os dados relativos ao consumo por ave/dia, em MS apresentaram o mesmo comportamento da $\mathrm{MN}$.

Os valores encontrados para o consumo neste experimento (média de 22,04 g com um mínimo de 16,93 g e um máximo de $26,80 \mathrm{~g}$ ) foram mais altos que os valores encontrados por Carciofi (1996) para papagaiosverdadeiros (mínimo de 12,40 e máximo de 19,1g por ave dia), trabalhando com uma dieta cujo valor de energia bruta era de $5940 \mathrm{kcal} / \mathrm{Kg} \mathrm{MS}$. 
TABELA 3 - Gasto ${ }^{1}$ (MN e MS) ${ }^{2}$ e consumo (MN, MS) diário das dietas experimentais (g) por ave²

\begin{tabular}{|c|c|c|c|c|}
\hline \multirow{2}{*}{ Dietas experimentais } & \multicolumn{2}{|c|}{ Gasto diário (g/ave/dia) } & \multicolumn{2}{|c|}{ Consumo diário (g/ave/dia) } \\
\hline & (MN) & (MS) & (MN) & (MS) \\
\hline Ração extrusada para psitacídeos & $37,91 \mathrm{a}$ & $34,78 \mathrm{a}$ & $23,06 \mathrm{ab}$ & $21,15 \mathrm{ab}$ \\
\hline Ração peletizada para psitacídeos & $71,55 \mathrm{a}$ & 64,66 a & $22,77 \mathrm{ab}$ & $20,58 \mathrm{ab}$ \\
\hline Ração comercial extrusada para psitacídeos & $112,35 \mathrm{a}$ & $102,34 \mathrm{a}$ & $29,42 \mathrm{ab}$ & $26,80 \mathrm{ab}$ \\
\hline Ração extrusada para cães linha prêmio & $31,83 \mathrm{a}$ & $29,40 \mathrm{a}$ & $18,33 \mathrm{a}$ & $16,93 \mathrm{a}$ \\
\hline Ração extrusada para cães linha econômica & $196,61 \mathrm{~b}$ & $179,47 \mathrm{~b}$ & $32,69 \mathrm{~b}$ & $29,84 \mathrm{~b}$ \\
\hline Semente de Girassol ${ }^{4}$ & $41,96 \mathrm{a}$ & $40,10 \mathrm{a}$ & $17,74 \mathrm{a}$ & $16,96 \mathrm{a}$ \\
\hline $\mathrm{CV}(\%)$ & 66,46 & 66,17 & 29,11 & 29,03 \\
\hline
\end{tabular}

1- Gasto = Consumo + desperdício.

2- $\mathrm{MN}=$ Matéria Natural, $\mathrm{MS}=$ matéria seca.

3- Valores em uma mesma coluna, seguidos de letras distintas, diferem pelo teste de $\mathrm{SNK}(\mathrm{P}<0,05)$.

4- Valores descontando o peso das cascas.

Quando os dados de gasto (MS) foram estabelecidos com base no peso metabólico das aves $\left(\mathrm{PV}^{0,75}\right)$, descritos na Tabela 4, a ração extrusada para cães linha econômica, ração comercial extrusada para psitacídeos e ração peletizada para psitacídeos apresentaram os maiores gastos $(368,38 \mathrm{~g}, 208,54 \mathrm{~g}$ e 138,51 $\mathrm{g}$, respectivamente), embora esta última não tenha diferido estatisticamente de todos os outros tratamentos. Os menores gastos $(\mathrm{P}>0,05)$ foram da ração extrusada para cães linha prêmio, ração extrusada para psitacídeos e semente de girassol $(56,22 \mathrm{~g}, 67,43 \mathrm{~g}$ e $82,63 \mathrm{~g}$, respectivamente) não diferindo entre si e o tratamento com a ração peletizada para psitacídeos.

As aves que se alimentaram da ração comercial extrusada para psitacídeos e da ração extrusada para cães linha econômica desperdiçaram mais ração, porém isto parece estar mais envolvido com o tamanho do grânulo que com a dieta em si, já que estas rações possuíam quase o dobro do diâmetro das outras rações. Percebeu-se durante o experimento, que vários papagaios seguram o grânulo com os dedos e o quebra o grânulo até ficar de um tamanho razoável para o seu bico. Dessa maneira, grande parte destas rações acaba caindo fora do comedouro, aumentando o desperdício.

O consumo diário de MS das rações extrusadas e peletizadas foi semelhante $(\mathrm{P}>0,05)$.

As aves que se alimentaram de rações específicas para psitacídeos, tiveram o mesmo consumo $(\mathrm{P}>0,05)$ das aves que ingeriram rações inespecíficas ou semente de girassol.

As aves que se alimentaram de dietas com maior concentração energética (semente de girassol e ração extrusada para cães linha prêmio) consumiram menos $(\mathrm{P}>0,05)$ que as aves que se alimentaram da ração extrusada para cães linha econômica e são as dietas que possuem um maior teor de energia metabolizável, 7215,0 e 4120,9 $\mathrm{kcal} / \mathrm{kg}$ de MS, e de energia metabolizável aparente corrigida pelo nitrogênio por kg de MS, respectivamente (Tabela 2). Por outro lado, a ração extrusada para cães linha econômica apresentou o menor valor de EMAn (3122,0 kcal/ $/ \mathrm{kg} \mathrm{MS}) \mathrm{e}$ o maior consumo $(\mathrm{P}>0,05)$ em relação às aves que se alimentaram da ração extrusada para cães linha prêmio e da semente de girassol (Tabela 5).

Os consumos de EMAn e de EMVn pelas aves que ingeriram semente de girassol (Tabela 5), 116,8 e 117,74 kcal $\mathrm{EM}$, respectivamente, foram semelhantes $(\mathrm{P}>0,05)$ àquelas que ingeriram ração extrusada para cães linha econômica $(89,9$ e 90,79 kcal de EMAn e EMVn) e ração comercial extrusada para psitacídeos (97,2 e 98,23 kcal de EMAn e EMVn).

Os valores encontrados para consumo de EMAn neste experimento (mínimo de 66,7 kcal e máximo de 116,8 kcal) situam-se próximos da faixa encontrada por Carciofi (1996) de 43,38 kcal (mínimo) e 101,26 kcal (máximo), que utilizou dois papagaios-verdadeiros em seu experimento (Tabela 5).

Os valores de EMAn e EMVn consumidos foram expressos também em $\mathrm{PV}^{0,75}$, sendo os resultados estatísticos entre tratamentos iguais aos resultados expressos em consumo diário por ave (Tabela 5).

Para comparar os valores de consumo de energia observados neste experimento com os valores preditos através de algumas fórmulas citadas por Carciofi (1996), adotou-se os valores médios de EMAn por $\mathrm{PV}^{0,75}$. As necessidades calóricas das aves seriam, então, de 127 $\mathrm{kcal} / \mathrm{kg} \mathrm{PV}{ }^{0,75}$, acrescida de $25 \%$ referente ao calor de digestão e absorção, resultando em $158,75 \mathrm{kcal} / \mathrm{kg} \mathrm{PV}^{0,75}$. 
TABELA4 - Gasto ${ }^{1}$ e consumo diário de matéria seca (MS) das dietas experimentais (g) por kg de peso metabólico (PV $\left.\mathrm{PV}^{0,75}\right)^{3}$

\begin{tabular}{lcc}
\hline \multicolumn{1}{c}{ Dietas experimentais } & Gasto diário (g/kg PV $\left.\mathbf{~ P V}^{\mathbf{0} 75} / \mathbf{d i a}\right)$ & Consumo diário (g/kg PV $\left.\mathbf{~}^{\mathbf{0} 75} / \mathbf{d i a}\right)$ \\
\hline Ração extrusada para psitacídeos & $(\mathbf{M S})$ & $(\mathbf{M S})$ \\
Ração peletizada para psitacídeos & $67,43 \mathrm{a}$ & $40,49 \mathrm{ab}$ \\
Ração comercial extrusada para psitacídeos & $138,51 \mathrm{ab}$ & $43,14 \mathrm{ab}$ \\
Ração extrusada para cães linha prêmio & $208,54 \mathrm{~b}$ & $54,02 \mathrm{ab}$ \\
Ração extrusada para cães linha econômica & $56,22 \mathrm{a}$ & $32,32 \mathrm{a}$ \\
Semente de Girassol & $368,38 \mathrm{~b}$ & $60,90 \mathrm{~b}$ \\
CV $(\%)$ & $82,63 \mathrm{a}$ & $34,65 \mathrm{a}$ \\
\hline
\end{tabular}

1 - Gasto $=$ Consumo + desperdício.

2- $\mathrm{MN}=$ Matéria Natural, MS =Matéria Seca.

3- Valores em uma mesma coluna, seguidos de letras distintas, diferem pelo teste de $\mathrm{SNK}(\mathrm{P}<0,05)$.

TABELA 5 - Consumo diário por ave de energia metabolizável aparente corrigida pelo nitrogênio (EMAn) e verdadeira corrigida pelo nitrogênio (EMVn) das dietas experimentais $(\mathrm{kcal})^{1}$.

\begin{tabular}{|c|c|c|c|c|}
\hline \multirow[t]{2}{*}{ Dietas experimentais } & \multicolumn{2}{|c|}{ Consumo diário (kcal/por ave) } & \multicolumn{2}{|c|}{$\begin{array}{l}\text { Consumo diário } \\
\text { (kcal/ } \mathbf{P V} 0,75 / \text { dia) }\end{array}$} \\
\hline & EMAn & EMAn & EMVn & EMVn \\
\hline Ração extrusada para psitacídeos & $71,3 \mathrm{a}$ & $136,5 \mathrm{a}$ & $138,3 \mathrm{a}$ & $72,2 \mathrm{a}$ \\
\hline Ração peletizada para psitacídeos & $66,7 \mathrm{a}$ & $139,8 \mathrm{a}$ & $141,9 \mathrm{a}$ & $67,7 \mathrm{a}$ \\
\hline Ração comercial extrusada para psitacídeos & $97,2 \mathrm{ab}$ & $196,0 \mathrm{ab}$ & $198,0 \mathrm{ab}$ & $98,2 \mathrm{ab}$ \\
\hline Ração extrusada para cães linha prêmio & 67,3 a & $128,5 \mathrm{a}$ & 130,3 a & $68,3 \mathrm{a}$ \\
\hline Ração extrusada para cães linha econômica & $89,9 \mathrm{ab}$ & $183,5 \mathrm{ab}$ & $185,3 \mathrm{ab}$ & $90,8 \mathrm{ab}$ \\
\hline Semente de Girassol ${ }^{2}$ & $116,8 \mathrm{~b}$ & $238,5 \mathrm{~b}$ & $240,5 \mathrm{~b}$ & $117,7 \mathrm{~b}$ \\
\hline $\mathrm{CV}(\%)$ & 31,86 & 32,77 & 33,15 & 32,16 \\
\hline
\end{tabular}

1 -Valores em uma mesma coluna, seguidos de letras distintas, diferem pelo teste de SNK ( $\mathrm{P}<0,05)$.

2-Valores na semente de girassol descorticada manualmente.

Neste caso, as aves que ingeriram rações extrusada e peletizada para psitacídeos e extrusada para cães linha prêmio apresentaram um consumo ligeiramente inferior ao recomendado $\left(136,5,139,8\right.$ e $128,5 \mathrm{kcal} / \mathrm{kg} \mathrm{PV}^{0,75}$, respectivamente), enquanto as que se alimentaram da ração comercial extrusada para psitacídeos e da ração para cães linha econômica apresentaram um consumo superior ao recomendado (196,0 e 183,5 kcal $/ \mathrm{kg} \mathrm{PV}^{0,75}$ ). Já a semente de girassol apresentou um consumo mais alto $(238,5 \mathrm{kcal})$, $50,24 \%$ acima do recomendado. O mesmo comportamento é observado quando se compara o resultado obtido com a fórmula citada por Nunes (1998), em que as necessidades calóricas de animais homeotérmicos, incluídas as aves, seriam de $140 \mathrm{kcal} \mathrm{EM}\left(\mathrm{PV}^{0,75}\right)$.

Já Drepper et al. (1988) preconizam a equação 200,8 kcal/ $\mathrm{kg} \mathrm{PV}{ }^{0,75}$. Neste caso as rações extrusada para psitacídeos $-\mathrm{A}$, peletizada para psitacídeos -B e de cães linha prêmio apresentaram um consumo muito inferior ao recomendado $\left(136,5,139,8\right.$ e $\left.128,5 \mathrm{kcal} / \mathrm{kg} \mathrm{PV}^{0,75}\right)$, enquanto que as rações extrusada para psitacídeos -C e a de cães linha econômica um consumo adequado (196,0 e 183,5 kcal/kg PV $\mathrm{PV}^{0,75}$ ). A semente de girassol apresentou um consumo ligeiramente mais alto ( $238,5 \mathrm{kcal})$, ou $18,77 \%$ acima do recomendado pela fórmula. Os consumos diários de proteína bruta, por ave e por $\mathrm{kg}$ de peso metabólico $\left(\mathrm{PV}^{0,75}\right)$, das dietas experimentais, estão apresentados na Tabela 6.

As aves que consumiram ração comercial extrusada para psitacídeos apresentaram uma ingestão de proteína bruta de 6,24 e $12,57 \mathrm{~g}$, respectivamente, entretanto este consumo foi semelhante $(\mathrm{P}>0,05)$ ao consumo de proteína das rações extrusadas para cães linha prêmio e extrusadas para cães linha econômica (4,85 e 5,49 g PB/ave/dia). 
TABELA 6-Consumo diário de proteína bruta (PB), por ave e por kg de peso metabólico $\left(\mathrm{PV}^{0,75}\right)$, das dietas experimentais ${ }^{1}$.

\begin{tabular}{lcc}
\hline \multicolumn{1}{c}{ Dietas experimentais } & \multicolumn{2}{c}{ Consumo diário de PB } \\
\cline { 2 - 3 } & Por ave & Por kg/ PV $^{\mathbf{0 , 7 5}}$ \\
\hline Ração extrusada para psitacídeos & $3,81 \mathrm{~b}$ & $7,29 \mathrm{~b}$ \\
Ração peletizada para psitacídeos & $3,58 \mathrm{~b}$ & $7,51 \mathrm{~b}$ \\
Ração comercial extrusada para psitacídeos & $6,24 \mathrm{a}$ & $12,57 \mathrm{a}$ \\
Ração extrusada para cães linha prêmio & $4,85 \mathrm{ab}$ & $9,25 \mathrm{ab}$ \\
Ração extrusada para cães linha econômica & $5,49 \mathrm{ab}$ & $11,20 \mathrm{ab}$ \\
Semente de Girassol & $4,06 \mathrm{ab}$ & $8,37 \mathrm{ab}$ \\
\hline CV (\%) & 29,15 & 30,29 \\
\hline
\end{tabular}

1- Valores em uma mesma coluna, seguidos de letras distintas, diferem estatisticamentepelo teste de $\mathrm{SNK}(\mathrm{P}<0,05)$.

Quando expresso em $\mathrm{PV}^{0,75}$, o consumo da ração comercial extrusada para psitacídeos foi semelhante ( $\mathrm{P}>0,05)$ às rações para cães $(9,25$ e 11,20 g de PB/ave/ dia, para linha prêmio e econômica, respectivamente), e à semente de girassol (8,37 g PB/ave/dia). Os papagaios que consumiram rações extrusadas para cães apresentaram consumos de proteína semelhantes $(\mathrm{P}>0,05)$ entre si e aos que consumiram as demais dietas testadas. As aves que ingeriram as rações extrusadas e peletizadas para psitacídeos apresentaram o mesmo consumo $(\mathrm{P}>0,05)$ de proteína bruta por ave/dia $(3,81 \mathrm{e}$ $3,58 \mathrm{~g}$ de $\mathrm{PB}$, respectivamente) e por peso metabólico (7,29 e 7,51 g de PB, respectivamente), sendo diferentes $(\mathrm{P}<0,05)$, somente da ração comercial extrusada para psitacídeos (12,57 g de PB).

As recomendações da AAFCO (1998) são de $12 \%$ de proteína bruta na dieta e as de Ullrey et al. (1991), de $22 \%$. Se considerarmos um consumo médio de $45 \mathrm{~g}$ de matéria seca por $\mathrm{kg}$ de $\mathrm{PV}^{0,75}$, as recomendações da AAFCO (1998) e Ullrey et al. (1991) podem ser expressas como 6,3 e 9,9 g de $\mathrm{PB}$ por $\mathrm{kg}$ de $\mathrm{PV}^{0,75}$, diariamente. Deste modo, todas as dietas testadas atenderiam bem as recomendações diárias sugeridas pela AAFCO (1998), mas somente as rações extrusada para psitacídeos $\mathrm{C}$ e as rações de cães atenderiam o recomendado por Ullrey et al. (1991).

$\mathrm{Na}$ Tabela 7, encontram-se os valores de Ca e P consumidos diariamente e expressos por ave e por $\mathrm{kg}$ de $\mathrm{PV}^{0,75}$. O consumo mais alto de $\mathrm{Ca}$ foi o das aves consumindo ração extrusada para cães linha econômica $(0,647$ e $1,315 \mathrm{~g}$ de $\mathrm{Ca}$ por ave e por $\mathrm{kg}$ de peso metabólico, respectivamente), diferindo $(\mathrm{P}<0,05)$ do consumo de $\mathrm{Ca}$ das demais dietas testadas. Por outro lado, a semente de girassol apresentou o consumo mais baixo $(0,012$ e $0,021 \mathrm{~g}$ de $\mathrm{Ca}$ por ave e por $\mathrm{kg}$ de peso metabólico, respectivamente), também diferindo $(\mathrm{P}<0,05)$ do consumo de $\mathrm{Ca}$ das demais dietas testadas. Já a ração extrusada para psitacídeos -C apresentou um consumo intermediário $(0,085$ e $0,163 \mathrm{~g}$ de Ca por ave e por $\mathrm{kg}$ de peso metabólico, respectivamente), mas diferente dos demais tratamentos.

Considerando um consumo médio de $45 \mathrm{~g}$ de matéria seca por kg de peso metabólico e a recomendação da AAFCO (1998) de níveis de 0,30 mínimo e a 1,20\% máximo de Ca na dieta, chega-se a uma ingestão adequada de 135 a $540 \mathrm{mg}$ de Ca por kg de peso metabólico. Sendo assim, todas as dietas atenderiam os níveis recomendados, com exceção à semente de girassol, bastante deficiente neste elemento.

Quanto ao fósforo, com exceção à ração extrusada para cães linha econômica, que apresentou um alto consumo $\left(0,327\right.$ e $0,667 \mathrm{~g}$ de $\mathrm{P}$ por ave e por $\mathrm{PV}^{0,75}$, respectivamente) diferindo das demais, todas as outras dietas apresentaram um consumo diário semelhante ( $\mathrm{P}>0,05)$, por ave e por peso metabólico. A AAFCO (1998) recomenda $0,30 \%$ de fósforo total (mínimo) para psitacídeos, o que resulta em $135 \mathrm{mg}$ de $\mathrm{P}$ total se considerarmos $45 \mathrm{~g}$ de consumo médio de matéria seca por $\mathrm{kg}$ de peso metabólico. Considerando esta recomendação o consumo de fósforo de todas as dietas foi adequado.

Tão importante quanto aos níveis consumidos de Ca e P, é a relação entre estes dois elementos na dieta consumida. Esta relação (Ca:P) situa-se entre 2:1 e 1:1 na dieta total, segundo a AAFCO (1998). A relação Ca: P muito baixa da semente de girassol $(0,06: 1)$ pode acarretar distúrbios graves, como, por exemplo, o hiperparatireoidismo secundário nutricional. 
TABELA 7 - Consumo diário de cálcio $(\mathrm{Ca})$ e fósforo $(\mathrm{P})$ em gramas, por ave e por kg de peso metabólico $\left(\mathrm{PV}^{0,75}\right)$, das dietas experimentais ${ }^{1}$.

\begin{tabular}{|c|c|c|c|c|c|}
\hline \multirow{3}{*}{ Dietas experimentais } & \multicolumn{4}{|c|}{ Consumo diário de Ca e $\mathbf{P}$} & \multirow{3}{*}{$\begin{array}{c}\text { Relação Ca:P } \\
\text { consumida }\end{array}$} \\
\hline & \multicolumn{2}{|c|}{ Por ave } & \multicolumn{2}{|c|}{ Por kg/ PV $\mathbf{P V}^{0,75}$} & \\
\hline & $\mathbf{C a}$ & $\mathbf{P}$ & $\mathbf{C a}$ & $\mathbf{P}$ & \\
\hline Ração extrusada para psitacídeos & $0,210 \mathrm{~b}$ & $0,185 \mathrm{~b}$ & $0,402 \mathrm{~b}$ & $0,353 \mathrm{~b}$ & $1,14: 1$ \\
\hline Ração peletizada para psitacídeos & $0,218 \mathrm{~b}$ & $0,183 \mathrm{~b}$ & $0,458 \mathrm{~b}$ & $0,383 \mathrm{~b}$ & $1,19: 1$ \\
\hline Ração comercial extrusada para psitacídeos & $0,085 \mathrm{c}$ & $0,158 \mathrm{~b}$ & $0,163 \mathrm{c}$ & $0,315 \mathrm{~b}$ & 0,53: 1 \\
\hline Ração extrusada para cães linha prêmio & $0,173 \mathrm{~b}$ & $0,183 \mathrm{~b}$ & $0,332 \mathrm{~b}$ & $0,348 \mathrm{~b}$ & $0,95: 1$ \\
\hline Ração extrusada para cães linha econômica & $0,647 \mathrm{a}$ & $0,327 \mathrm{a}$ & $1,315 \mathrm{a}$ & $0,667 \mathrm{a}$ & $1,96: 1$ \\
\hline Semente de Girassol $^{2}$ & $0,012 \mathrm{~d}$ & $0,178 \mathrm{~b}$ & $0,021 \mathrm{~d}$ & $0,365 \mathrm{~b}$ & $0,06: 1$ \\
\hline $\mathrm{CV}(\%)$ & 25,13 & 26,27 & 25,75 & 27,12 & \\
\hline
\end{tabular}

1- Valores em uma mesma coluna, seguidos de letras distintas, diferem pelo teste de $\mathrm{SNK}(\mathrm{P}<0,05)$.

2- Valores na semente de girassol descorticada manualmente.

\section{CONCLUSÕES}

Os resultados obtidos neste estudo permitem as seguintes conclusões: 1- os consumos médios de MS foram influenciados negativamente pelo teor de energia metabolizável da dieta; 2 - o alto consumo das aves recebendo semente de girassol sugere que, além da densidade energética, a palatabilidade da dieta tem grande influência no consumo voluntário; 3- todas as dietas testadas atenderam as necessidades diárias de proteína bruta e de fósforo; 4- o consumo de cálcio da semente de girassol não atendeu a necessidade diária do elemento; 5o tamanho do pelet parece interferir no gasto e desperdício de alimentos pelos papagaios.

\section{REFERÊNCIAS BIBLIOGRÁFICAS}

AMERICAN SOCIETY FOR TESTINGAND MATERIAL. ASTM standards for bomb calorimetry. Philadelphia, 1971.

ASSOCIATION OF AMERICAN FEED CONTROL OFFICIALS INCORPORATED. Nutrition expert panel review: new rules for feeding pet birds. Official Publication - Feed Management, Atlanta, v. 49, n. 2, 1998.

CARCIOFI, A. C. Avaliação de dieta à base de sementes e frutas para papagaios (Amazona sp): determinações da seletividade dos alimentos, consumo, composição nutricional, digestibilidade e energia metabolizável. 1996. 104 f. Dissertação (Mestrado) - Faculdade de Medicina Veterinária e Zootecnia, Universidade de São Paulo, São Paulo, 1996.
CARCIOFI, A. C.; SAAD, C. E. P. Nutrition and nutritional problems in wild Animal. In: FOWLER, M. E.; CUBAS, Z. S. Biology, medicine, and surgery of South American wild animals. Ames: Iowa State University, 2001. p. 425-434.

CUNNIFF, P. (Ed.). Official methods of analysis of AOAC International. 16. ed. Arlington: AOAC International, 1995. v. 1.

DREPPER, K.; MENKE, H.; SCHULZE, G.; WACHTERVORMANN, U. Untersuchungen zum protein-und energiebedarf adulter wellensittiche (Melopsittacus undulatus) in käfighaltung: studies on the protein and energy requirement of adult budgerigars housed in cages. Kleintierpraxis, [S.1.], v. 33, n. 2, p. 57-62, 1988.

LUMEIJA, J. T.; ZIJP, N. M. N.; SCHIPPERS, R. The acceptance of a recently introduced extruded parrot food in the Netherlands. Israel Journal of Veterinary Medicine, The Aviv, v. 51, n. 3/4, p. 161-164, 1996.

MACHADO, P. A. R.; SAAD, C. E. P. O futuro das rações para aves ornamentais e silvestres no Brasil. Aves - Revista Sul Americana de Ornitofilia, Belo Horizonte, v. 3, p. 37-40, 2000.

NUNES, I. J. Nutrição animal básica. 2. ed. Belo Horizonte: FEP-MVZ, 1998.388 p.

SAAD, C. E. P. Avaliação de alimentos e determinação das necessidades de proteína para manutenção de papagaiosverdadeiros (Amazona aestiva). 2003. 160 p. Tese (Doutorado) - Universidade Federal de Minas Gerais, Belo Horizonte, 2003. 
SAAD, C. E. P.; MACHADO, P. A. R. Utilização de óleos e gorduras em rações para aves ornamentais e silvestres. Aves - Revista Sul Americana de Ornitofilia, Belo Horizonte, v. 4, p. 23-26, 2000.
SAS INSTITUTE.SAS user's guide: statistics. Cary, 1995. 956 p.

ULLREY, D. E.; ALLEN, M. E.; BAER, D. J. Formulated diets versus seed mixtures for psittacines. Journal of Nutrition, Philadelphia, v. 121, n. 11S, p. 193-205, 1991. 